\title{
Apresentação
}

\section{0 anos das operações de paz das Nações Unidas: balanços e perspectivas}

\author{
Geraldine Marcelle Moreira Braga Rosas Duarte ${ }^{1}$ \\ Ricardo Oliveira dos Santos ${ }^{2}$
}

DOI: 10.5752/P.1809-6182.2018v15.n3.pl

Recebido em: 15 de maio de 2019 Aceito em: 15 de maio de 2019

Criada no pós-Segunda Guerra Mundial para "preservar as geraçôes vindouras do flagelo da guerra”, e tendo como propósito primário manter a paz e a segurança internacional, a Organização das $\mathrm{Na}$ ções Unidas (ONU) encontrou nas Operações de Manutenção da Paz (OMP) uma importante ferramenta para evitar ameaças à paz sistêmica e reprimir os atos de agressão ou qualquer ruptura da paz entre os Estados (NAÇÓES UNIDAS, 2001, p. 3). Seguindo a tradição das operaçôes militares de baixa intensidade conduzidas sob a égide da Liga das Nações, as OMP autorizadas pela ONU concentraram seus esforços, inicialmente, em atividades de mediação e negociação. Entre os anos de 1948 a $1989^{3}$ dezoito OMP foram desdobradas seguindo esses parâmetros. Com exceção da Operação de Paz das Nações Unidas no Congo (ONUC), da Autoridade Executiva Temporária das Naçóes Unidas na Nova Guiné Ocidental (UNTEA), e do Grupo de
Assistência Transitória das Nações Unidas (UNTAG), as Naçôes Unidas investiram em missões de observação e forças de interposição ao longo de quatro décadas durante a Guerra Fria. O objetivo basilar dessas ações multilaterais "tradicionais", seguindo os princípios da "trindade santa", como o consentimento, imparcialidade e uso mínimo da força, era o de observar a aderência das partes ao cessar-fogo e acordo de paz, além de facilitar entendimentos locais e interromper combates entre Estados beligerantes.

Com o fim da Guerra Fria, no início da década de 1990, a ONU seria palco de um conjunto de transformações significativas que impactariam os princípios e as diretrizes das OMP nos anos seguintes. A partir do período em questão, o sistema internacional testemunhou uma redução significativa dos conflitos interestatais e um aumento exponencial dos conflitos intraestatais. Contrariamente

1. Professora de Relações Internacionais, Departamento de Relaçôes Internacionais da Pontifícia Universidade Católica de Minas Gerais (PUC-Minas), Belo Horizonte/Brasil. ORCID 0000-0001-8133-806X.

2. Professor de Relaçôes Internacionais, Instituto de Relaçôes Internacionais da Pontifícia Universidade Católica do Rio de Janeiro (PUC-Rio), Rio de Janeiro/Brasil. ORCID 0000-0001-8788-2103.

3. Além das Operaçóes de Manutenção de Paz, o Conselho de Segurança autorizou duas operaçóes militares durante o mesmo período: nas Coreias, entre 1950-1953, e a ação naval do Reino Unido na Rodésia nos anos de 1966-1975 (LOWE, 2008, p. 673). Tanto a Assembleia Geral quanto o Secretariado também desenvolveram suas próprias missões neste mesmo intervalo de tempo: além da já mencionada UNSCOB e UNTEA, há também a Comissão das Nações Unidas para a Índia e o Paquistão (1948-1951), a Comissão de Observação para a Hungria (1956-1957), a Autoridade Executiva Temporária das Naçôes Unidas na Nova Guiné Ocidental (1962-1963), a Missão de Investigação no Irã (1984-1988) e a Missão de Observadores das Naçôes Unidas na Nicarágua (19891990) (LOWE, 2008, p. 673-674). Para uma relação das Operações de Paz conduzidas fora dos auspícios das Naçôes Unidas durante a Guerra Fria, ver: BELLAMY, Alex J. \& WILLIAMS, Paul D. Trends in Peace Operations, 1947-2013. In: KOOPS, Joachim A. et al (Eds.). The Oxford Handbook of United Nations Peacekeeping Operations. Oxford: Oxford University Press, 2015. pp. 13-42. 
às guerras de procuraçáo ideológica, ocasionadas pela rivalidade entre o bloco capitalista e soviético, os conflitos internos baseiam-se em fragmentaçóes étnicas, clivagens tribais, sectarismos religiosos e movimentos secessionistas. Adicionalmente, tais embates começaram a ser travados em contextos majoritariamente urbanos e não mais fronteiriços, resultando no alto envolvimento de civis, principalmente os grupos mais vulneráveis - como mulheres e crianças. Nesse cenário de erosão das condições de sociabilidade civil e retração do espaço humanitário, há uma massiva violação dos direitos humanos, resultando, por exemplo, em numerosos casos de crimes de guerra, limpeza étnica e genocídio.

$\mathrm{O}$ arcabouço de tarefas desenvolvidas pelos mantenedores da paz até então se mostrava insuficiente para garantir um ambiente seguro e estável em sociedades afetadas pela guerra. Não havia uma paz a ser mantida e, em muitos casos, tropas de exércitos nacionais que deveriam ser evacuadas. A privatização da guerra, marcada pela emergência de atores não estatais como vetores de fomento do conflito, levariam a uma reorientação do foco de resposta das OMP. Sendo pressionada a responder a tais crises e a assumir um papel não mais reativo, mas sim proativo na gestão e resolução das "emergências complexas" ${ }^{1}$, as Nações Unidas atravessaram um processo de desenvolvimento normativo e institucional ao longo dos últimos trinta anos. Relatórios, resoluçóes e projetos desde a Agenda para a Paz (1992) até o "Cruz Report" (2017) reformulariam os princípios básicos das OMP, provocando uma multidimensionalidade e abrangência de

1. David J. Keen na obra "Complex Emergencies" define emergências complexas como um momento no qual a situação humanitária se encontra em risco, e que geralmente está ligado a um quadro de conflito violento de larga escala - como por exemplo, guerra civil, limpeza étnica e genocídio (KEEN, 2008, p. 1). Keen esclarece que é necessário relacionar este termo com conflitos internos e externos e náo o confundir com desastres naturais. Em outras palavras: emergências complexas ocorrem tanto no nível doméstico quanto internacional e são provocados pela ação humana, não pela natureza (enchentes, furacões etc.) (KEEN, 2008, p. 1). resposta onusiana. O conjunto desses documentos avançam a ideia de que a tradicional lógica militar de resposta das OMP durante a Guerra Fria era inadequada para garantir a paz, segurança e estabilidade político-econômico-social em Estados considerados "frágeis", "falidos" ou "colapsados". O pilar civil e policial, este último responsável pelo estado democrático de direito, deveriam ser de igual modo incorporados à estrutura de uma OMP. Essa integração de capacidades permitiria a provisão, por exemplo, de direitos humanos, proteção de civis, assistência eleitoral, açóes anti-minas e políticas voltadas para gênero. $\mathrm{O}$ alargamento nos mandatos deveria abarcar também atividades de desarmamento, desintegração, desmobilização, reintegração e reinserção de antigos combatentes, e, não exaustivamente, a repatriação de civis não combatentes. Em alguns casos, como na Administração Transitória das Nações Unidas em Timor Leste (UNTAET), as Naçóes Unidas assumiriam a plena autoridade soberana de modo a governar o território timorense durante a transição à independência e autogoverno.

A despeito dos avanços doutrinários, organizacionais, de treinamento, pessoal e logísticos ocasionados por sucessivas reformas entre 1990 e 2010 , as Nações Unidas se defrontam recorrentemente com desafios estratégicos, operacionais e táticos. De maneira semelhante, o nexo entre segurança, ajuda humanitária e desenvolvimento, expresso na "paz liberal" por tais avanços normativos, são marcados por um histórico recente de insucessos. Analistas como Marc Sedra argumentam que as iniciativas de construçấo da paz, seguindo os princípios liberal-democráticos e enraizados nos modelos estatais ocidentais weberianos, privilegiam normas liberais de governança que são inteligíveis face às múltiplas realidades locais de arranjos políticos, econômicos,

2. Para uma tipologia acerca dos Estados falidos, ver: TRAUSCHWEIZER, Ingo \& MINER, Steven M. (Eds). Failed States and Fragile Societies: A New World Disorder? Athens: Ohio University Press, 2014. 224 p. 
sociais e culturais (SEDRA, 2017, p. 303). Acrescenta que o modelo vigente de peacebuilding é extremamente tecnocrata, "desempoderando" vozes locais e interesses, tratando os Estados receptores como uma página em branco. Essa abordagem de cima para baixo desrespeita autoridades, instituiçóes indígenas e complexas estruturas de poder sociais, considerando, dessa forma, apenas os interesses dos doadores externos do Norte global em detrimento da comunidade local em si (SEDRA, 2017, p. 34).

Os dilemas e dificuldades enfrentados na implementação da Reforma do Setor de Segurança (SSR) em Estados afetados por conflitos armados incidem diretamente na vontade política dos Estados membros das Naçóes Unidas no que tange à participaçáo envolvendo pessoal. Do outro lado do espectro tático, a partir do prisma político, essa falta de disposição certamente afeta a elaboração dos mandatos e a consecuçáo das atividades previstas pelo Conselho de Segurança, Assembleia Geral e Secretariado. Como fatores atenuantes, somam-se fatores externos à própria ONU, tais como "o reequilíbrio das relaçóes entre os Estados do Sul e Norte global, que demandam uma revisão dos métodos vigentes de construção da paz; a ascensão de organizaçóes regionais como provedoras da paz, desenvolvendo seus próprios arranjos de segurança; o aumento da violência extrema e fundamentalista de atores não estatais; e a significativa demanda de atores não estatais na ênfase de uma abordagem centrada na segurança humana” (PETER, 2019, p. 5).

Como forma de reverter esse cenário adverso, o atual Secretário-Geral da ONU, António Manuel de Oliveira Guterres, iniciou em 2018 um processo de revitalização e renovação política das OMP. Para tanto, em 16 de agosto publicou a Declaração de Compromissos Compartilhados sobre as Operaçôes de Manutenção da Paz das Naçóes Unidas. O documento tem como principal finalidade reavivar o compromisso dos Estados membros da organização com as causas da paz e segurança internacional. Adicionalmente, conclama as organizaçóes regionais a renovarem seus esforços em prol do fortalecimento das OMP.

Para alcançar esses objetivos, Guterres estabelece eixos centrais de engajamento coletivo que se baseiam nos vários planos de ação e recomendaçôes contidas em resoluçóes e documentos-projetos das Naçóes Unidas desde o ano 2000. Com isso, o Secretário-Geral encoraja que o Conselho de Segurança e demais órgãos da organização avancem em soluções políticas na gestão e resolução de conflitos, de modo a fortalecer o impacto político dos capacetes azuis no terreno. A Declaração, ecoando o Relatório do Painel Independente de Alto Nível sobre Operaçóes de Paz (2015), reafirma a primazia política para superar os conflitos intraestatais. Da mesma forma, face às constantes falhas na proteção de civis em zonas de litígio, as Naçóes Unidas e seus parceiros devem fortalecer tais mecanismos de proteção fornecidos pelos peacekeepers. Dialogando com o Relatório "Improving Security of United Nations Peacekeepers: We need to change the way we are doing business" ou "Santos Cruz Report", Guterres sugere da mesma forma que a ONU deve incrementar a segurança e proteção de seu pessoal militar, policial e civil. No contexto dos crescentes desafios impostos por elementos hostis, como as células terroristas, os capacetes azuis devem estar mais bem equipados para responderem à ação descentralizadora desses grupos. Repercutindo a política de transparência da organização, o Secretário Geral estabelece como prioridade de reforma a efetiva clareza de todos os componentes das OMP, garantindo, entre outros pontos, sua efetividade. Similarmente, estimula o fortalecimento da conduta de todo o seu pessoal no contexto de uma operação de paz. Entre os outros pontos elencados, não menos importantes, merece destaque a construção de uma paz sustentável, 
através do fortalecimento do ownership local e a importância de parcerias com organizações regionais como forma de elevar a capacidade de resposta às crises complexas que demandam recursos políticos e econômicos consideráveis (UNITED NATIONS ACTIONS FOR PEACEKEEPING, 2019).

No mês seguinte à publicação da Declaração, Guterres organizou um Painel de Alto Nível para a Ação das Operaçóes de Manutenção da Paz (A4P) com o propósito de garantir a aderência às diretrizes propostas pelo documento e avançar na sua implementação. Até o presente momento, aderiram voluntariamente aos compromissos da Declaração cento e cinquenta Estados membros ${ }^{3}$ e quatro organizaçōes regionais: União Europeia (UE), Organização Internacional da Francofonia (OIF), Comissão da Uniāo Africana (UA) e Organização do Tratado Atlântico Norte (OTAN).

Nesse contexto de ação, a Resolução 2436 do Conselho de Segurança, entre outros pontos, congratula os esforços do Secretariado no sentido de atualizar o modus operandi dos mecanismos de segurança coletiva das Naçóes Unidas no novo século; além disso, compromete-se em criar quadros de referência que reflitam as novas necessidades dos mantenedores da paz face à complexa realidade do terreno; além de reforçar o compromisso do Conselho em diferentes níveis para incrementar a proteção de civis e a manutenção da paz e segurança de forma duradoura e sustentável (NAÇÔES UNIDAS, 2018).

Diante da perspectiva em tela, a ONU encontra-se atualmente diante de uma dinâmica de revisão de diretrizes e princípios das OMP para os próximos anos. Com a crescente aderência aos compromissos compartilhados, espera-se que o novo paradigma seja implementado ao longo dos próximos anos. Tal expectativa decorre do envolvi-

3. Para a relação completa dos Estados, ver: https://peacekeeping.un.org/en/action-for-peacekeeping-a4p mento ativo por parte dos membros do Conselho de Segurança, Secretariado, contribuintes de tropas militares e policiais, bem como parceiros regionais e contribuintes financeiros. Sendo assim, é de extrema relevância refletir sobre alguns dos pontos presentes na Declaração. Com vistas a contribuir para esse momento de mudança normativa e institucional no campo da segurança coletiva internacional, o presente dossiê explora as oportunidades e limitações no avanço de tal paradigma, centrado em eixos como proteção de civis, uso da força, gênero, capacidade e performance e, ainda, a paz sustentável todos esses temas sendo considerados os eixos prioritários de consideração entre os atores relevantes no teatro de uma operação de paz. O conjunto de artigos reunidos nessa edição nos possibilita refletir criticamente sobre esses e outros pontos conexos da agenda das OMP.

Os textos de Laura Donadelli \& Leonardo Dias e de Gustavo Macedo \& Kaiutan Silveira discorrem sobre a evoluçáo do uso da força no contexto das OMP multidimensionais. Laura e Leonardo destacam as implicaçóes político-legais, operacionais e estratégicas da alta intensidade militar prevista nas operaçôes de estabilização das Nações Unidas a partir do início do século XXI. Gustavo Macedo e Kaiutan Silveira discorrem sobre o contexto e conteúdo do "Santos Cruz Report", bem como a reação da comunidade internacional face a alguns elementos do documento que enfatizam o alto nível da força no contexto das OMP. Ambas as pertinentes reflexōes fomentam o necessário debate sobre o tenso e difícil equilíbrio entre soluções políticas e militares como garantidoras do sucesso de uma operaçáo de paz.

Inserido nos debates sobre a paz liberal e suas contradiçóes para o alcance de uma paz sustentável e duradoura, Ana Rachel Fortes, a partir do estudo de caso de Angola (1988-2002), discorre sobre a racionalidade neoliberal envolta nas OMP contem- 
porâneas. Por fim, diante do crescente engajamento de Estados do Sul Global e seu ativo papel na reformulação de algumas normas de construção da paz, Diana Viveiros aponta algumas ambiguidades desses Estados, a partir do estudo de caso do Brasil, contrastando seu engajamento nas Nações Unidas e no Conselho de Defesa Sul-Americano. Acreditamos que este dossiê representa um importante espaço de reflexão sobre os desdobramentos do desenvolvimento normativo e institucional em curso das Naçōes Unidas, iniciado na conjuntura do seu septuagésimo aniversário.

\section{Referências}

KEEN, David J. Complex Emergencies. Cambridge: Polity Press, 2008.

LOWE, Vaughan et al. (Eds.). Appendix 1: UN Peacekeeping Operations, 1945-2006. In: LOWE, Vaughan et al. (Eds.). The United Nations Security Council and War: The Evolution of Thought and Practice Since 1945. Oxford: Oxford University Press, 2008a. pp.666-687.

NAÇŌES UNIDAS. Carta das Naçóes Unidas e o Estatuto da Corte Internacional de Justiça. Rio de Janeiro: Centro de Informação das Naçōes Unidas, 2001.

NAÇÓES UNIDAS. Conselho de Segurança. S/RES/2436: Resolution. New York: 2018. Disponível em: <https://undocs.org/S/RES/2436(2018)>. Acesso em: 12 de maio de 2019.

PETER, Mateja. UN Peace Operations: Adapting to a New Global Order? In: Cedric de Coning and Mateja Peter (Eds.). United Nations Peace Operations in a Changing Global Order. New York: Palgrave Macmillan, 2019.

SEDRA, Mark. Security Sector Reform in Conflict-Affected Countries: The Evolution of a Model. London and New York, Routledge, 2017.

UNITED NATIONS ACTION FOR PEACEKEEPING. Action for Peacekeeping. Disponível em: < https://peacekeeping.un.org/en/action-for-peacekeeping-a4p>. Acesso em: 12 de maio de 2019. 